\title{
Histoplasmosis: A Case Report
}

\author{
Shahtaj Khan*, Saiqa Zahoor, Saliha Akbar, Shujaat Gul and Humaira Taj \\ Hayatabad Medical Complex, India
}

Submission: July 07, 2017; Published: July 21, 2017

*Corresponding author: Shahtaj Khan, Hayatabad Medical Complex, India, Email: shahtajmasood@yahoo.com

\begin{abstract}
Histoplasmosis (also known as "Cave disease, Darling's disease, Ohio valley disease, reticuloendotheliosis,) is a disease caused by the fungus Histoplasma capsulatum. Histoplasma capsulatum is found in soil, often associated with decaying bat guano or bird droppings. Disruption of soil from excavation or construction can release infectious elements that are inhaled and settle into the lung. Symptoms of this infection vary greatly, but the disease affects primarily the lungs. Occasionally, other organs are affected; this is called disseminated histoplasmosis, and it can be fatal if left untreated. Histoplasmosis is common among immunocompromised patients. In immunocompetent individuals, past infection results in partial protection against ill effects if reinfected. Here we present this case of histoplasmosis to provide insight of the disease to the physician as clinical manifestation of the disease is similar to those in community acquired pneumonia, tuberculosis, sarcoidosis and malignancy.
\end{abstract}

Keywords: Histoplasmosis; Histoplasma capsulatum

\section{Case Report}

Patient name $\mathrm{ABC} 40$ years old male resident of district Buner, Swat has been referred to haematology deptt of Hayatabad Medical Complex Peshawar on $20^{\text {th }}$ May 2017. He had low grade fever and cough for the last two months. There was no history of transfusion. On examination he was pale with hepatosplenomegaly with no lymphadenopathy. The patient was given broad spectrum antibiotics and antimalarials. His peripheral blood findings showed RBC count of $3.21 \times 10^{6} / \mu \mathrm{l}, \mathrm{Hb}$ of $7.5 \mathrm{~g} / \mathrm{dl}$ and TLC of $6.12 \times 10^{3} / \mu \mathrm{l}$ with DLC of neutrophils $73 \%$, lymphocytes $29 \%$, monocytes $2 \%$, eosinophils $4 \%$, myelocytes $2 \%$. Platelets count was $100 \times 10^{3} / \mu$ l. Peripheral smear examination revealed microcytic hypochromic blood picture. His other lab investigations were unremarkable with anti HCV antibodies positivity.

His bone marrow examination revealed hyper cellular marrow with normal erythropoiesis and mylopoiesis and increased megakaryocyte. Intracellular and extracellular microorganisms were seen. The organisms showed positivity with iron stain. Trerphine biopsy showed cellular marrow with intact trillineage haematopoiesis. There was diffused infiltrate of marrow by intracellular and extracellular microorganisms. Peripheral blood, bone marrow aspiration and trephine biopsy findings were suggestive of Histoplasma capsulatum. Discussion

Histoplasmosis was originally discovered in Panama by Samuel D [1]. It is now known to be endemic in North and South America with low prevalence in South East Asia and Africa [2]. Histoplasmosis is most common endemic mycosis and major cause of morbidity in immunocompromised patients who live in endemic areas [3]. H. capsulatum grows in soil and material contaminated with bird or bat droppings (guano). The fungus has been found in poultry house litter, caves, areas harbouring bats, and in bird roosts. The fungus is thermally dimorphic: in the environment it grows as a brownish mycelium, and at body temperature $\left(37^{\circ} \mathrm{C}\right.$ in humans) it morphs into a yeast. Histoplasmosis is not contagious, but is contracted by inhalation of the spores from disturbed soil or guano. The inoculum is represented principally by microconidia. These are inhaled and reach the alveoli. $\mathrm{n}$ the alveoli, macrophages ingest these microconidia. They survive inside the phagosome. As the fungus is thermally dimorphic, these microconidia are transformed into yeast. They grow and multiply inside the phagosome. The macrophages travel in lymphatic circulation and spread the disease to different organs [4] (Figure1 \& 2). 


\section{Current Trends in Biomedical Engineering \& Biosciences}

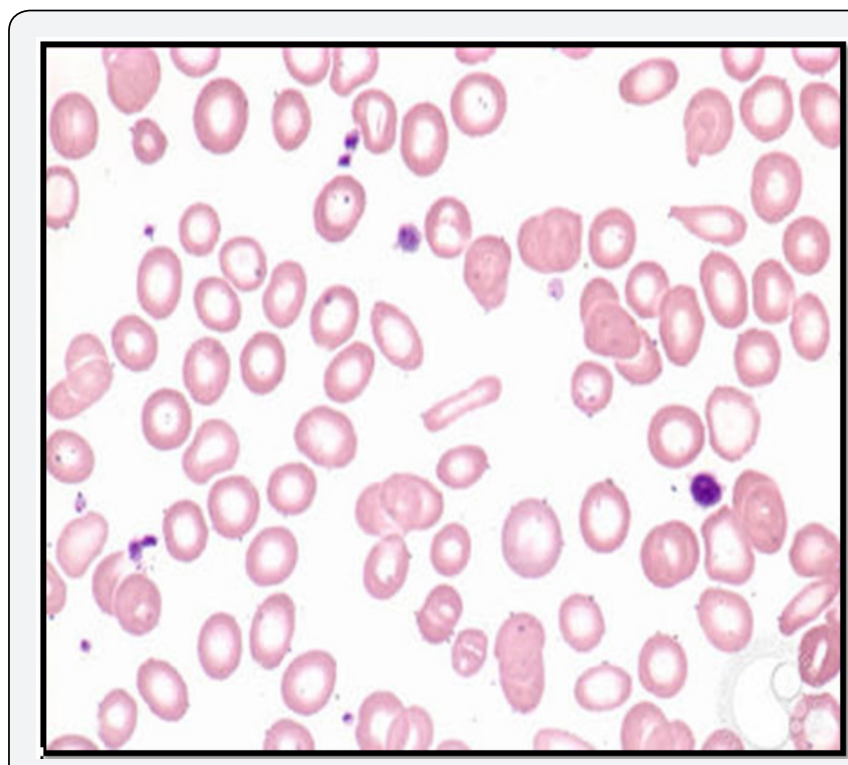

Figure 1: Peripheral Smear.

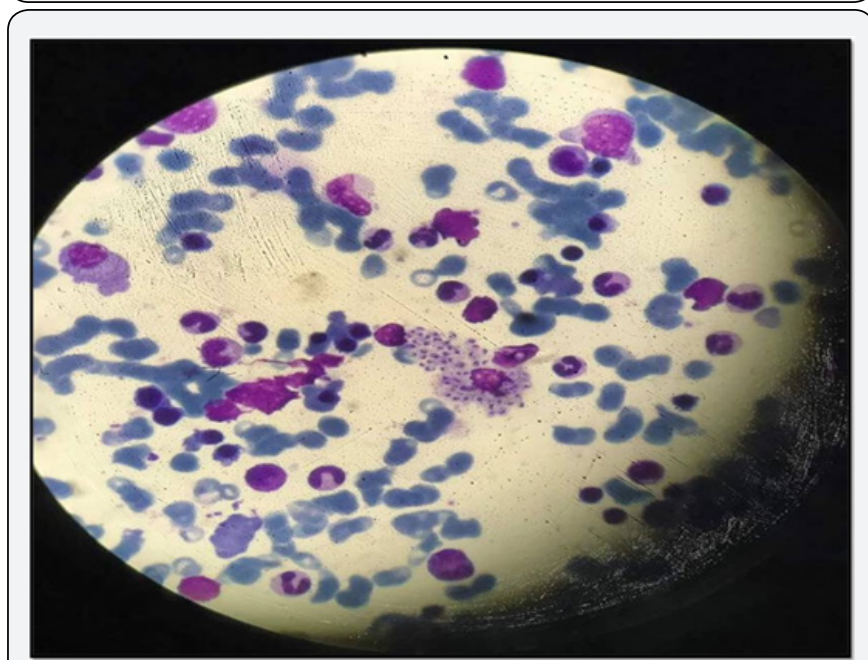

Figure 2: Bone Marrow Aspirate.

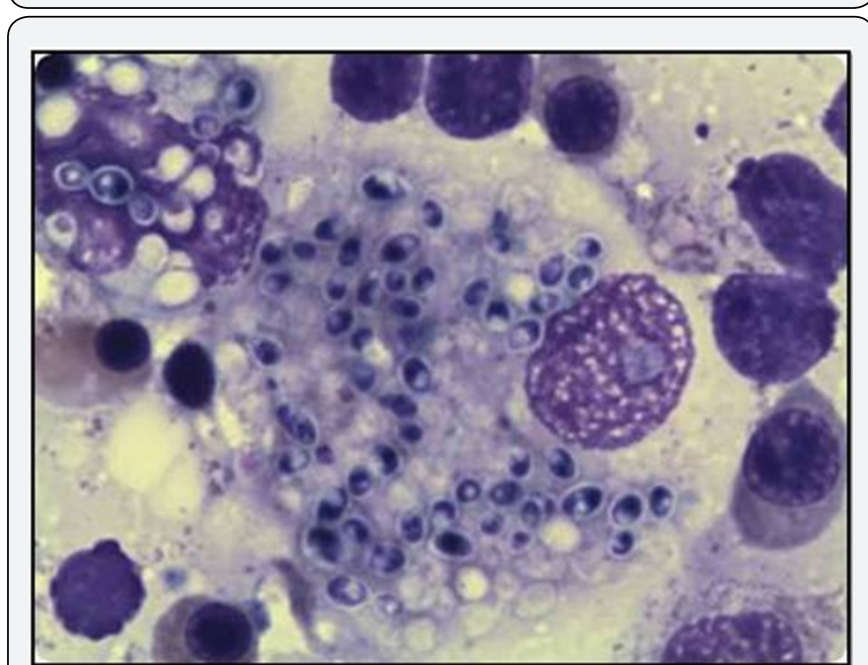

Figure 3: Bone Marrow Aspirate.

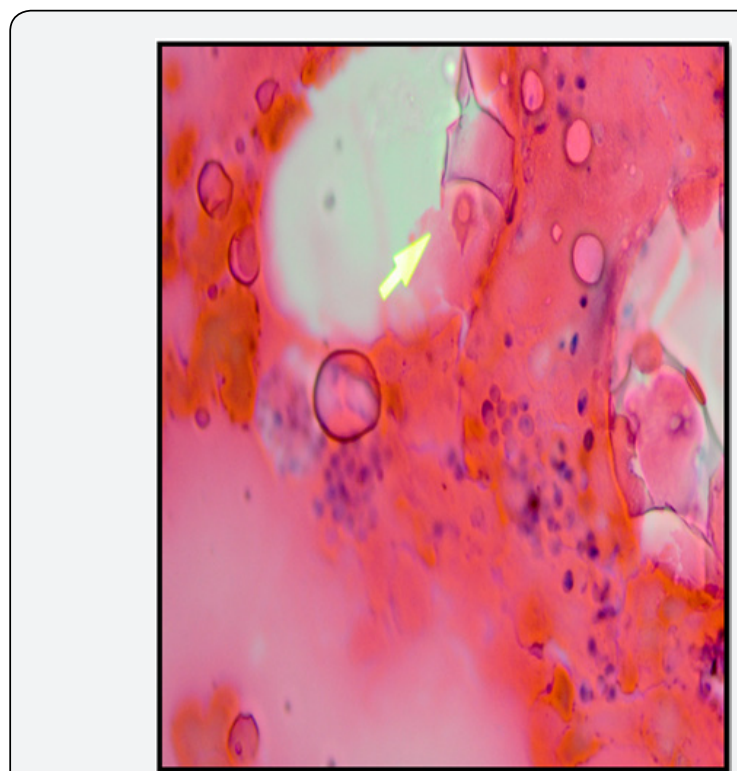

Figure 4: Iron Stain (Perl's Stain)

The signs and symptoms of infection occurs 3-17 days after the exposure. Most effected individuals have clinically silent manifestations and show no apparent ill effects [5]. Acute phase of histoplasmosis is characterised by nonspecific respiratory symptoms often cough and flu like. Chronic histoplasmosis cases resembles tuberculosis [6,7]. Disseminated histoplasmosis effects multiple organs and is fatal unless treated [8]. While histoplasmosis is the most common cause if mediastinitis but this remains a rear disease. Severe infections can cause hepatosplenomegaly, lymphadenopathy and adrenal enlargement [4]. Lesions have a tendency to calcify as it heals. A battery of investigations is required for the diagnosis. In this regard, antigen for $H$. capsulatum detection is most rapid and sensitive assay in histoplasmosis [9]. The $H$. capsulatum antigen is found in bronchioalveolar leavage fluid in pulmonary histoplasmosis and CSF in meningitis cause by histoplasmosis. PCR is also a rapid and specific tool but is not routinely used [10]. Serological tests includes antibodies to $H$. capsulatum measured by immunodiffusion or complement fixation. However the definite diagnosis is achieved by direct microscopic examination of body specimens like peripheral blood, bone marrow and bronchial aspirate after staining with Gimsa or periodic acid of Shiff (PAS) [11]. H. capsulatum appears as tiny round or oval bodies $1-4 \mu \mathrm{m}$ in diameter with a clear hallow surrounding central or acentric stained chromatin. The organism is found both intracellularly and extracellularly [9]. Culture is the gold standard for H. capsulatum diagnosis. Blood cultures using lysis centrifugation techniques or instrumental blood culture technique such as BACTEC or Becton Dickinson are more effective as compared to standard culture (sabouraud or agar medium) [9-11]. Both techniques require 4-6 weeks to grow the fungal colony, initially are smooth and as ages become cottony and brown. Microscopically they have speared hyphae. 
Lipid formulations of Amphotericin B 3-5mg/kg/d, given for one to two weeks, followed by itraconazole $200 \mathrm{mg}$ three times daily for three days then twice daily for 3 months induces a rapid response and should be used in patients sufficiently ill to require hospitalization. Methylprednisolone $(0.5-1.0 \mathrm{mg} / \mathrm{kg} / \mathrm{d}$ intravenously) is also recommended for those with hypoxemia or respiratory distress. Itraconazole $200 \mathrm{mg}$ twice daily for 2 weeks followed by once or twice daily for 3 months is recommended in patients with milder illnesses, and has proven to be effective in controlled trials in patients with disseminated and chronic pulmonary infection [12,13] (Figure 3 \& 4).

\section{References}

1. Darling ST (1906) A protozoan general infection producing pseudotubercles in the lungs and focal necrosis in the liver, spleen and lymphnodes. J Am Med Assoc 46: 1283-1285.

2. Assi MA, Sandid MS, Baddour LM, Roberts GD, Walker RC (2007) Systemic Histoplasmosis: A 15-Year Retrospective Institutional Review of 111 Patients. Medicine (Baltimore) 86(3): 162-169.

3. Davis AM, Pierson RN, Loyd JE (2001) Mediastinal fibrosis. Sem Resp Infect 16(2): 119-130.

4. Ryan KJ, Ray CG (2004) Sherris Medical Microbiology. (4 $4^{\text {th }}$ edn), McGraw Hill, pp. 674-676.

5. Silberberg P (2007) Radiology Teaching Files: Case 224856 (Histoplasmosis)

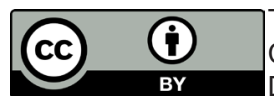

This work is licensed under Creative Commons Attribution 4.0 License DOI: 10.19080/CTBEB.2017.05.555675
6. Tong P, Tan WC, Pang M (1983) Sporadic disseminated histoplasmosis simulating military

7. tuberculosis. Br Med J 287(6395): 822-823.

8. Toussaint G, Marty P, Le Fichoux Y, Loubière R (1987) Histoplasmosed' importationà Histoplasmacapsulatum, donnéesbiocliniqueset thérapeutiquesvariées, à propos de trois casobservésdans les Alpesmaritimes. Bull Soc Fr Mycol Med 16(1): 87-90.

9. Kauffman CA (2007) Histoplasmosis: a clinical and laboratory update. Clinical Microbiology Reviews 20 (1): 115-132.

10. Guimarães AJ, Nosanchuk RM (2006) Zancopé-Oliveira, Diagnosis of histoplasmosis. Brazilian Journal of Microbiology 37(1): 1-13.

11. Rickerts V, Bialek R, Tintelnot K, Jacobi V, Just-Nübling G (2005) Rapid PCR-Based Diagnosis of Disseminated Histoplasmosis in an AIDS Patient. Eur J Clin Microbiol and Infec Diseases 21(11): 821-823.

12. Couppié P, Aznar C, Carme B, Nacher M (2008) American histoplasmosis in developing countries with a special focus on patients with HIV: diagnosis, treatment, and prognosis. Curr Opin Infect Dis 19(5): 443449 .

13. Dismukes WE, Bradsher RW, Cloud GC, Kauffman CA, Chapman SW, et al. (1992) Itraconazole therapy for blastomycosis and histoplasmosis. Am J Med 93(5): 489-497.

14. Wheat J, Hafner R, Korzun AH, Limjoco MT, Spencer P, et al. (1985) Itraconazole treatment of disseminated histoplasmosis in patients with the acquired immunodeficiency syndrome. Am J Med 98: 336342 .

Your next submission with Juniper Publishers
will reach you the below assets
- Quality Editorial service
- Swift Peer Review
- Reprints availability
- E-prints Service
- Manuscript Podcast for convenient understanding
- Global attainment for your research
- Manuscript accessibility in different formats
( Pdf, E-pub, Full Text, Audio)
- Unceasing customer service
Track the below URL for one-step submission
https://juniperpublishers.com/online-submission.php

